\title{
OPEN
}

\section{4 \\ Costs and Revenues of Audiovisual Products}

\begin{abstract}
The analysis of the costs and revenues concerning audiovisual products is the starting point of any theory of value and is instrumental to the understanding of pricing and financial dynamics of the audiovisual industry and single companies. In this chapter different types of costs related to the production and distribution of audiovisual products, as well as possible revenue sources, are analysed, distinguishing between TV products, films and audiovisual web products. The chapter is not intended to be a mere classification of costs, nor a handbook on the costs and revenues measures. It is rather an attempt to build a methodology to analyse the economics of the audiovisual industry.

La Torre, Mario. The Economics of the Audiovisual Industry: Financing TV, Film and Web. Basingstoke: Palgrave Macmillan, 2014. DOI: 10.1057/9781137378477.0009.
\end{abstract}




\subsection{Introduction}

In market practice, the value of an audiovisual product can be expressed both as a cost, when referring to the production stage, and as a price, when referring to the negotiation stage. The analysis of the costs and revenues concerning audiovisual products is the starting point of any theory of value and is instrumental to the understanding of pricing and financial dynamics of the audiovisual industry and single companies. In this chapter different types of costs related to the production and distribution of audiovisual products, as well as possible revenue sources, are analysed distinguishing between TV products, films and audiovisual web products. The chapter is not intended to be a mere classification of costs, nor a handbook on the costs and revenues measures. It is rather an attempt to build a methodology to analyse the economics of the audiovisual industry.

\subsection{Typologies of costs and sources of revenues}

The overall cost of an audiovisual product may be divided into different types of spending. It is possible to distinguish five categories of costs: (a) pre-production costs related to the development of the project, (b) artistic production costs, (c) technical production costs, (d) post-production costs and (e) distribution costs (Figure 4.1 and Table 4.1).

PRE-PRODUCTION COSTS

ARTISTIC PRODUCTION COSTS

TECHNICAL PRODUCTION COSTS

POST-PRODUCTION COSTS

DISTRIBUTION COSTS

FIGURE 4.1 Typologies of costs of audiovisual products 
TABLE 4.1 The costs of audiovisual products

\begin{tabular}{ll}
\hline TYPOLOGIES OF COSTS & COST ITEMS \\
\hline PRE-PRODUCTION COSTS & Storyline and Screenplay \\
& Preparation: \\
& Project Research and Development \\
& Feasibility Study \\
& Pre-recruitment of Technical and \\
& Artistic Resources \\
ARTISTIC PRODUCTION COSTS & Director \\
TECHNICAL PRODUCTION COSTS & Cast \\
& Producer Fee \\
& Editing \\
& Crew \\
& Extra Talent \\
Wardrobe \\
Set \\
POST-PRODUCTION COSTS & Location \\
& Transportation \\
& Pusic \\
& Publicity \\
& Fringes \\
& Insurance \\
& Equipment \\
& Post-production Film \& Lab \\
Editing \\
\end{tabular}

The pre-production costs are attributable to the creative idea at the very core of an audiovisual project, to the feasibility study of the project, to its development up to the first supply of technical and artistic resources necessary for the production. The cost of the creative idea is represented mainly by the cost of so-called "plot or storyline" and the subsequent screenplay.

The storyline and screenplay can be original and created ad hoc, original but already existing, or non-original and derived from literary works - in the last two cases the cost coincides with the purchase price of the plot rights, the screenplay rights, or the rights to the literary work.

Production costs are divided into artistic costs - generally referred to the director and main actors - and technical costs that include all the costs related to the crew engaged in the production, location costs, set and wardrobe, as well as the costs of advertising and promotion.

Post-production costs comprise all costs related to the editing of the film, in particular images and sound editing, and special effects. 
Distribution costs relate to both the costs of accessing a specific distribution platform through which the public may watch the product and the costs of communication and marketing.

The extent of individual cost items, and its significance as the percentage of the overall budget are strongly dependent on the product typology. Audiovisual products, despite being subject to the same manufacturing process, are the result of a mix of artistic and technical elements that will differ for different types of products. Moreover, strategic choices may have an impact on the nature of production costs and their extent.

The analysis of costs, therefore, should be conducted with reference to the type of product and to the priority distribution channel.

When analysing the revenues, it is important to clarify how audiovisual products fall into the category of "experience goods", from an economic point of view, and in that of "intangible assets", from an accounting point of view. In other words, audiovisual products are goods expressing an intangible value related to the emotional satisfaction of the audience and, for this reason, are classified as "experiential goods". This explains why the capacity of an audiovisual product to generate revenues depends directly on the will of the public to pay for the possibility to watch the product, and thus transforms itself from potential audience to actual viewers. The more actual-paying viewers an audiovisual product attracts, the more revenues it generates. Therefore, the revenues are related to the product's capacity to attract paying viewers on various markets of exploitation.

The nature and volume of revenues generated by an audiovisual product are linked to the economic exploitation of the product, and the product, in turn, is linked to the channels used by the public to watch it. Exploitation rights for an audiovisual product refer to the right of economic exploitation of the same.

Therefore, exploitation rights may not coincide with the ownership of the work, but still they entitle their holder to economic exploitation of the product, meaning the possibility to obtain revenues from its sale or from licensing the right to it.

The main forms of economic exploitation coincide with the main and most widespread forms of watching audiovisual products: cinema, television, home video and the web. The access to different markets of exploitation is linked to different market practices and regulatory constraints that define a precise timing of usability of the audiovisual 




FIGURE 4.2 Windows of exploitation

product through various forms of exploitation: the time slots dedicated to different exploitation markets are called "windows" (Figure 4.2). In an international context, the windows have different durations but the chronological sequence of exploitation is sufficiently harmonized and, for a product which can access all forms of exploitation, mainly cinema works, the first window is the movie theatre, followed by Home Video (HD), Pay TV, PPV, Free TV, and other ancillary and derivatives markets, including the ones related to new technologies: new Media and Video on demand (the so called "VOD"). These new technological markets allow a non-linear and interactive use of a work. The most important among ancillary markets are merchandising, advertising (the use of images or sequences of images to promote products), sponsorship (the use of images or their sequences linked to the sponsor's name), premium promotion (use of promotional items relating to characters distributed freely for promotional purposes regarding products or services) and recording (separate use of the work and the soundtrack). The most important among derivative markets are those exploiting the rights for sequel, prequel, remake, spin-off (a work derived from an already existing work that focuses on one of the characters and develops a whole new plot) and novelization (adaptation of a story from another medium).

Foreign market is a specific source of potential revenue regarding the possibility of selling the rights to exploit a work in a country other than that in which it was produced, and so it is independent from the timing of other windows of exploitation.

The new tendencies in the audiovisual market, and the subsequent creation of hybrid cross media products, result in the traditional linear pattern of windows of exploitation becoming less representative. The access timing to the windows is becoming more and more irregular and there is an increasing number of products which are meant for one specific window only (Figure 4.3).

Technical and artistic characteristics of a product determine also its potential access to exploitation markets. Different products will have different capacities to generate revenues, also with reference to different exploitation markets (Figure 4.4). 


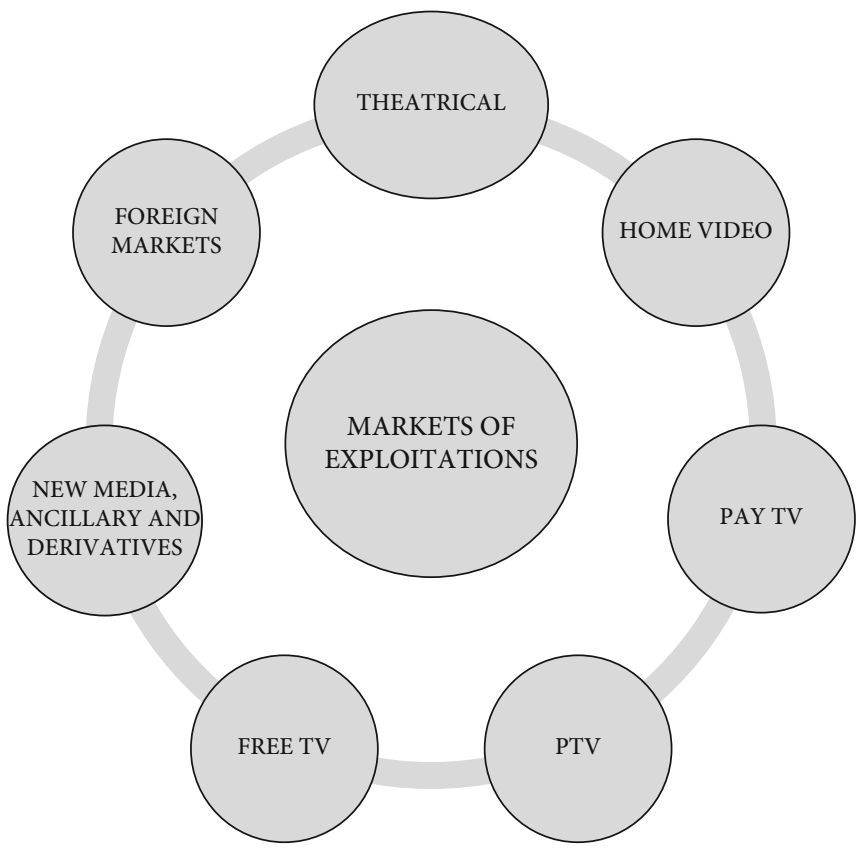

FIGURE 4.3 Markets of exploitations



FIGURE 4.4 Major markets of exploitations by audiovisual products 
As a matter of fact, film products may be classified as products with a longer cycle of exploitation, as they are potentially able to access all forms of exploitation. The audience may watch a film both in the cinema and on TV, as well as in Home Video mode or through modern technologies on new channels based on Internet connection. On the contrary, TV and web products are usually characterized by a limited number of exploitation channels, even if the new generation of cross media products is going to picture a different landscape for the next future. The possibility of accessing a foreign market, and its significance in terms of percentage in the revenues in relation to the overall revenue generated by a work, is a peculiar characteristic of only a few products. Products' internationality depends on various factors: artistic qualities of the product, including both the universality of the story and the popularity of the cast and director.

Finally, it should also be clarified why a major number of potential exploitation channels does not necessarily coincide with major economic potential. And it is due to the fact that some exploitation channels are more profitable than others. On the other hand, however, there are also those forms of exploitation that do not generate any revenue at all.

In the light of the above mentioned, the analysis of costs and revenues generated by an audiovisual product should be conducted by examining some of the peculiarities distinguishing television, cinema and web products.

\subsection{Costs and revenues of TV products}

\section{Costs of TV products}

There is a clear correlation between the typology of a TV product, its artistic quality, its production model and the nature and extent of costs it generates (Figure 4.5).

When considering the typology of a product in relation to the costs and their significance, the most visible differences emerge between
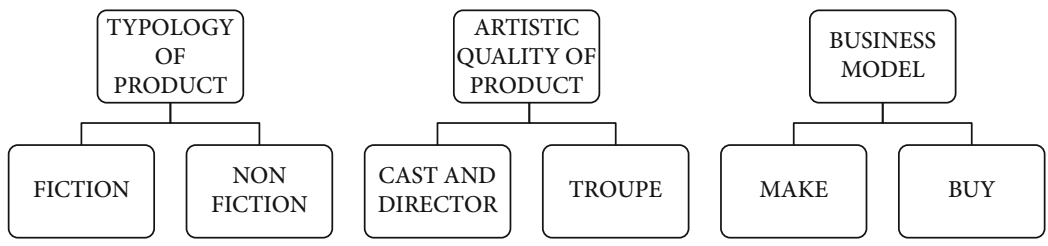

FIGURE 4.5 Determinants of costs for TV products 
fiction and non-fiction. While the costs of fiction products are generated throughout the entire production process (pre-production, artistic and technical production, post-production), for non-fiction products the pre- and post-production costs are much less significant.

In general terms, low pre-production costs are a result of the absence of the creative element in non-fiction productions. Also, non-fictional programmes are usually broadcasted live, which significantly reduces the post-production costs. However, there are cases in which non-fiction productions do generate significant pre-production costs and it usually happens with productions based on formats purchased from third parties - the purchase of exploitation rights being the main component of pre-production costs.

The relative significance of individual cost items, on the other hand, rather than being a function of the nature of TV product, is usually a function of the quality standard of the product, and often is strongly dependent on the artistic and technical crew engaged in the production. Therefore, it can be affirmed that the cost items that have the greatest impact on the production budget are artistic and technical production costs. Naturally, the value of these cost items, and their percentage in the total budget, depend mainly on the artistic element and not on the type of programme. Engaging well-known and acclaimed directors and actors increases the budget of fiction productions. But there are also examples of news that generate higher costs when compared to entertainment shows only because an influential journalist is involved.

The cost of a programme is also related to the production model adopted by a television company. In order to satisfy the need for new programmes, a TV company may either make them or buy them and, therefore, decide on one of the following:

a. in-house production: the TV company produces and finances the production;

b. co-production: the TV company participates in the production and covers only a part of the total production costs;

c. commissioned production: the production is contracted to third-party independent executive producers, but financed by the TV company;

d. purchase: the TV company purchases programmes from other producers/broadcasters.

The above-mentioned alternatives differ in terms of the nature of production costs and their extent (Figure 4.6). In the case of in-house production or co-production, the television company will directly incur 


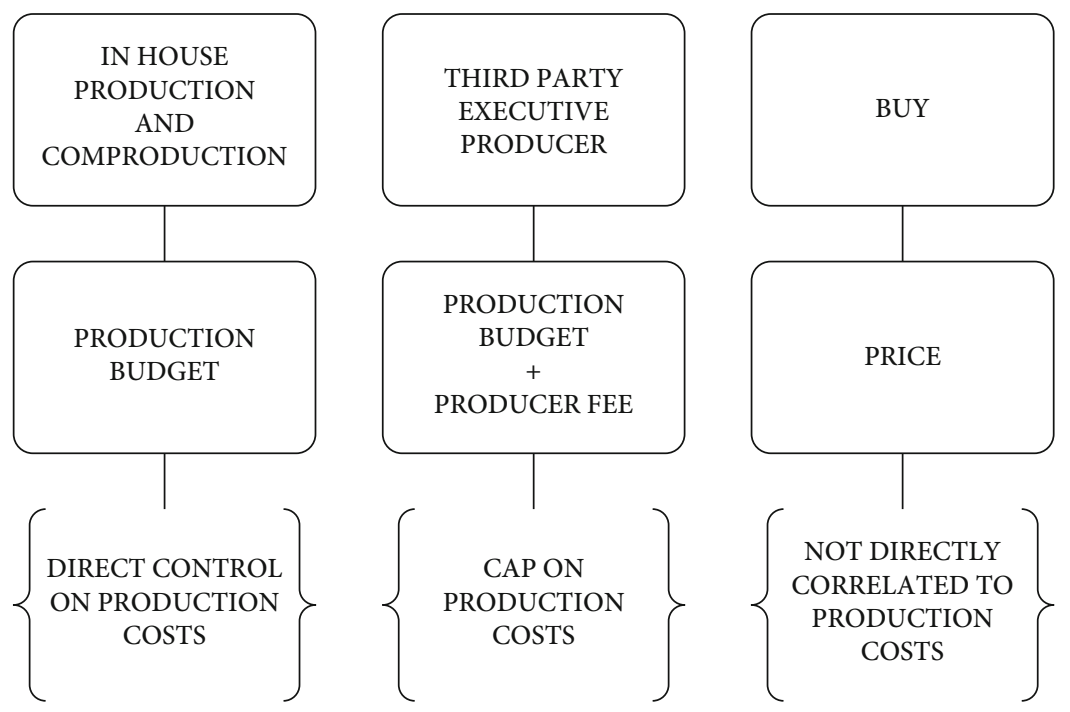

FIGURE 4.6 Costs and business models for TV products

the total production cost or its share in the production costs. In the case of a production commissioned to an executive producer, the costs are always covered by the TV company (the contractor), including a fee for the executive producer (the contracting). These two options differ in terms of a degree of control that the TV company has over the production costs: direct and independent control in the first option; indirect control dependent on the ability of the executive producer in the latter one. TV companies usually establish a cap on production costs that the third party producer needs to observe and any additional costs are covered by the executive producer - which means that the costs incurred by the commissioning company do not change.

When purchasing a programme, the product cost is the purchasing price, which may be uncorrelated to the production costs. The determinants of prices and costs for TV products represent key factors in the theory of value of audiovisual products and are the fundamental variables in explaining the pricing of these products ${ }^{1}$.

At this point, it is necessary to explain why the choice of a business model for TV products is primarily based on variables of editorial and strategic nature, rather than on economic ones. From the editorial 
point of view an in-house production is always the first choice for those programmes that are supposed to be easily associated with the company's brand, or if the company wants to maintain a direct control over its content. Therefore, for editorial reasons, in-house production involves usually non-fictional programmes, customarily news. Such an approach is justified also by some strategic variables. A decision to outsource production is a medium- to long-term strategic choice because it has an impact on the entire company's structure and on its balance sheet.

It should be noted that purchase costs (buy alternative) are usually bigger but more flexible whereas production costs (make alternative) are significantly more rigid. Producing in house, rather than commissioning or purchasing, means developing structures and skills which will probably lead to a substantial increase in overhead expense.

The need to brand news and information programmes and to assure availability of the product when needed for programming is not so urgent in the case of fiction products. When it comes to fiction, the decision whether to make or to buy is strictly based on economic variables, and the cost-benefits analysis involves the following factors:

a) the extent and rigidity of the fixed costs related to the in-house production;

b) the purchase price, including all kinds of fees due to any third parties and intermediaries.

If the demand for a given product declines, the buy alternative allows greater flexibility to change one's mind and take a different course of action. Deciding on the make alternative can be justified only in case of information products and news - strongly linked to the brand - and in case of those fiction products that ensure significant production volumes and long-term audience loyalty.

For these reasons, the main television broadcasters (including the four national television networks in the USA: ABC, NBC, CBC, Fox) produce only a limited number of programmes in-house, commissioning the production of fiction to film companies, and the production of entertainment shows to audiovisual production companies.

Finally, even if the make alternative results more convenient in terms of costs-benefits analysis, one should also consider the financial sustainability of the choice. The investment needed for in-house production may be unsustainable for the company, as it may require too high initial investment with revenues diluted over time. This element is of fundamental 
importance for the understanding of the coherence of the purchase price of an audiovisual product, and it also explains why the purchasing price is usually high. And therefore, even if the cost of in-house production results lower when compared with the purchase cost, the company may still decide on buy alternative keeping in mind the strategic flexibility it guarantees in case of any change in market trends. Higher costs incurred in time $t$ would thus be compensated by minor costs of changing strategy in time $t+1$. In the medium-term, the cost-benefit analysis may lead to the conclusion that the buy alternative is cheaper. In the medium- to longterm, it may be more convenient to opt for the purchase even at costs higher than those of an in-house production. Such a perspective may lead a TV company to accept high purchase prices, even those exceeding significantly the costs of in-house production.

In general terms, it can be observed that: (a) television companies decide on in-house production when it comes to news and information programmes; (b) the most frequently chosen business models for entertainment programmes are commissioned production and in-house production; (c) commissioning, co-production and purchase are alternatives mostly applied to fiction.

In conclusion, it can be stated that (Figure 4.7):
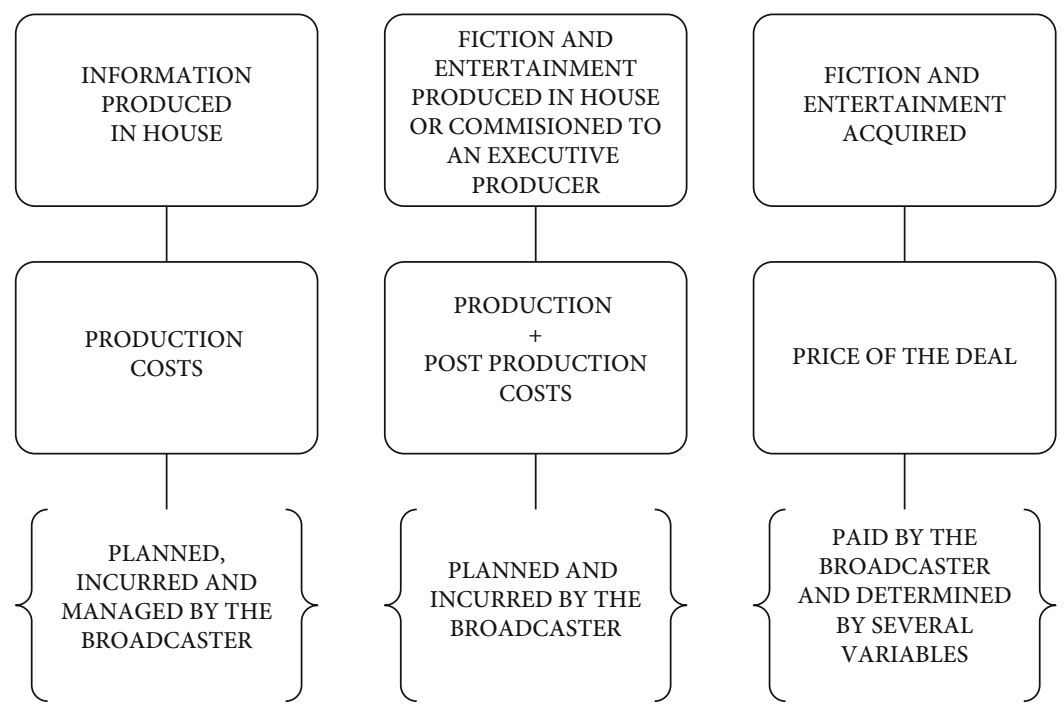

FIGURE 4.7 Costs of TV products by typology and business models 
a) news and information programmes are usually made in-house and broadcasted live - the costs are incurred directly by the television company and refer mainly to the production stage;

b) fiction and entertainment programmes can be produced in-house or commissioned - the costs are incurred directly by the television company and refer to all production stages;

c) fiction and entertainment products can be acquired - the cost is the purchase price and its determinants are diverse and different, depending on the product and on the territory, and are conditioned by historical periods and economic cycles.

\section{Revenues of TV products}

The natural media outlet for television products is television itself. Recently, certain television products falling into the fiction category can also be found in Home Video and other markets, mainly VOD.

With reference to in-house production, co-production and commissioned production, the original owner of exploitation rights is the television broadcaster. In the case of purchase, the television company acquires the right of exploitation from the original producer or from a third party who owns such rights.

Broadcasting revenues, regardless of whether the product has been acquired or produced in-house, consist mostly of advertising revenues attributable to that product. Advertising revenues depend not only on the typology of the product but also on its capacity to attract audience, as well as its position in programme schedule and, therefore, on its time slot and the channel on which it is aired. These are the variables taken into consideration by the advertisers when deciding on airing their commercials within a given programme and on charge rates they are willing to pay for it ${ }^{2}$.

For the producer, or a third party owner of exploitation rights, television revenue is embodied in the sale price of the exploitation right to a broadcaster who intends to air the programme. The price is influenced by the potential advertising revenue associated with the product.

In brief, it is possible to state that the revenues deriving from television exploitation rights of an audiovisual product are directly and indirectly linked to the advertising revenues that a broadcaster is able to obtain from the product. It is not possible to draw a clear distinction between products of fiction and non-fiction when it comes to their capacity of 
generating revenues. Advertisers assess attractiveness of a given product by analysing both historic and estimated audience data. With the exception of certain specific events - such as national or international sporting championships - there are no rules that would explain why some programmes are more attractive than others. Some types of audiovisual products primarily destined for television exploitation are fortunate to penetrate also other markets, like Home Video, VOD or foreign markets. However, with very few exceptions, these forms of exploitations are decidedly of a marginal significance in terms of revenues.

Finally, it might be useful to explain how the governance model of the television broadcaster affects sales of individual products (Figure 4.8). Revenues of a public television broadcaster derive not only from advertising, but also from Government grants and from local authorities' contributions. Public broadcasters and pay TV also have the advantage of having an additional revenue source that is TV license fees and subscriptions. These additional revenue sources determine different business models and financial cycles of public television, when compared to commercial television, as they do not refer to a single product but to the entire range of products offered by a given television company. In these circumstances it becomes a matter of complicated analysis estimating revenue generated by a single product. On one hand, the methods used by broadcasters to define the portion of the



FIGURE 4.8 Revenues of TV products 
additional resources attributable to the individual product are influenced by a large margin of discretion; on the other hand, the availability of these resources impacts on the exploitation value of the single product: the price that the broadcaster is willing to pay to buy the product is inevitably affected by the portion of public contribution attributed to the product itself.

\subsection{Costs and revenues of cinema products}

As for the nature and typology of costs and revenues, it is useful to divide cinema products into traditional fiction productions, animated feature films, documentaries and short films.

\section{Costs of cinema products}

The four categories of cinema products involve the same cost typologies as those analysed for television products. There are, however, some differences in terms of individual cost items and their significance as, for example, the distribution costs.

Therefore, costs of cinema products can be classified in two typologies: the costs that are strictly related to production and those related to distribution (Figure 4.9).

Costs of cinema products vary in size and time, depending on the project and on the market: the average production and distribution cost of European films is much lower than the American ones and this is usually explained by the different dimension of the potential revenues of the USA films.

PRODUCTION COSTS

- PRE-PRODUCTION

- PRODUCTION

- POST-PRODUCTION
DISTRIBUTION COSTS

- PRINT

- ADVERTISEMENT

- MINIMUM GUARANTEE

FIGURE 4.9 Costs of cinema products 
Production costs: similarly to TV products, production costs can be divided, per time of expenditure, into pre-production, production and post-production, according to time scheduling (Table 4.1).

Average costs of feature films are much higher than those of animated films, documentaries and short films. There are, however, examples of big-budget animated feature films and those of low-budget feature films.

In general terms, it is possible to identify the production costs as the primary outflows regarding a film project. The cost items that weigh heavily on the production budget of feature films include director and cast, artistic and technical crew, and lab costs. In the case of documentaries and animated feature films the absence of costs regarding actors lowers the significance of artistic production costs with an increase in development and post-production costs. Short films, usually produced by young artists taking their first steps in the film industry, reflect in terms of costs, a very low-budget feature film and are often characterized by a productive structure of amateur nature that relies strongly on voluntary contributions of the cast and crew and on low-cost services.

Distribution costs of cinema products regard all the activities necessary to access cinemas, as well as all the advertising and promotional activities, which are all part of film distribution. Distribution costs are connected to all the activities aimed at releasing the film on screen in a given territory, such as acquisition of the exploitation rights to the film (so called "minimum guarantee") and the costs incurred by its distributor for the dubbing, as well as for the promotion and launch (Table 4.2).

For feature films and animated films, the cost items that mainly affect the distribution costs are dubbing, printing of copies and advertising (mainly through posters, newspapers and television).

Distribution costs of documentaries and short films are characterized by a different significance and composition, as these two film categories are known to be suffering a constant difficulty in accessing cinema distribution.

\section{Revenues of cinema products}

Revenues are linked to the capacity of cinema products to penetrate different markets of exploitation. There are noticeable differences between feature films, animations, documentaries and short movies. 
TABLE 4.2 Distribution costs of cinema products

\begin{tabular}{ll}
\hline COST TYPOLOGIES & COST ITEMS \\
\hline $\begin{array}{l}\text { DISTRIBUTION RIGHTS } \\
\text { Acquisition of distribution rights }\end{array}$ & Minimum guarantee paid by the distributor \\
EDITING & \\
$\begin{array}{l}\text { Dubbing } \\
\text { Subtitles }\end{array}$ & Dialogue adaptation/Dubbing \\
Censorship & \\
Printing & Filming/ Trailer \\
LAUNCH & \\
Advertising & Posters/Flyers \\
Press Office & Press book/Photographs/Press Conference \\
TV/Radio Spot & \\
Web & \\
Premieres and Events & \\
Merchandising & \\
\hline
\end{tabular}

Feature films are the category characterized by the most complex and varied composition of revenues, owing to their capacity to access different exploitation markets. Virtually, a feature film can access all forms of exploitation existing in various markets. Documentaries are usually screened through television or Home Video; only few feature-length documentaries have the opportunity to access movie theatres. The screening of short films takes place during specialized film festivals or through culturally oriented cinema networks.

Once again, it is important to emphasize how the temporal order of the exploitation windows, characterizing the distribution market of audiovisual products since World War II, is becoming increasingly blurred. A growing number of irregularities has been observed regarding the time and sequence of accessing different markets, as well as time of permanence of a given product on the market. While in the past the access windows outlined a linear distribution process, nowadays the distribution model is rather circular. Access to individual markets has become dependent on the product characteristics, and not on the order of priority established by law or market practices. The modern distribution model, therefore, emphasizes even more the differences between products that were designed and created for specific markets only and universal products. The first group of products finds its access channel only to specific markets, while the second one to the whole distribution 
chain. Both groups access markets in a non-linear manner, but according to distribution strategy and to the audience response (Figure 4.3).

The current trend results in a new blend of the quantitative and qualitative dimension of revenues. In the past, the breakdown of the traditional sources of revenue on the European film market has seen in theatrical the main market of exploitation of rights, followed by Home Video, DVD and television. Since World War II, the characteristic feature of the European film market has been a definite concentration of revenues on specific markets of exploitation. In the United States, by contrast, the market has ensured a greater diversification of revenues and, what is more important, a greater balance between theatrical revenues, Home Video and DVD. Research conducted by IMCA in 2001, on behalf of the European Commission, on a sample of 120 films (108 of European origin and 12 from the USA) revealed that $77 \%$ of the total revenue generated by European films derived from theatrical exploitation, $14 \%$ from Video and DVD, 3\% from Pay TV and 5\% from Free TV. In the USA, the situation was completely different - theatrical exploitation generating only $34 \%$ of total revenues, Home Video and DVD 41\%, Pay TV 17\% and Free TV $9 \%^{3}$. These results are no longer representative of the current situation that can no longer be described by a rigid revenues composition. Each individual product has a unique range of features that determine their potential penetration of different markets. And the markets themselves are subject to a cyclicality of their profitability.

\subsection{Costs and revenues of audiovisual web products}

\section{Costs of audiovisual web products}

Costs of audiovisual web products reflect the same categories of costs typical of television and cinema products. The production process does not differ in any way, neither in nature, nor in its temporal order. The pre-production, production and post-production costs are a common feature of audiovisual web products as well.

Nevertheless, the nature and the extent of costs are in a way affected by the specific characteristic of web products and of their producer. Here we can distinguish two models. The traditional one is characterized by the circumstance that authors and producers are represented by the same person, or the same group of people. Web products are the 
result of a handyman author who realizes all stages of the production process and, for this reason is commonly called the "filmmaker". Thus, a filmmaker is the person who performs both purely authorial functions, as well as productive and distributive ones. It is common that filmmaking teams are formed essentially on the basis of friendship relationships and shared interests. The control over all production stages allows the filmmakers to measure the costs of a given product and relate them to the available financial means. As filmmakers are usually independent young talents gaining their first professional experience, web products are usually low-budget products. Taking into consideration the nature and the extent of costs, it is possible to make a distinction between artistic production costs, referring to all authors of the product, and technical production costs, which depend on the financial capacities of filmmakers themselves, while distribution costs are reduced almost to zero (Figure 4.10). Web products are exclusively designed for being distributed within the web, while the virality of the web allows for a free marketing campaign.

The costs measure is also strongly affected by the duration of the product. In this perspective, and taking into consideration how vast the range of web audiovisual products is, it is possible to notice significant differences of costs, even between products of the same type, which are due to the product's duration. As an example, a web series can be composed of episodes that may vary from 30 seconds to 20 minutes.

Exceptions to the model described above can be observed in two emerging trends: OTT productions and marketing and communication-
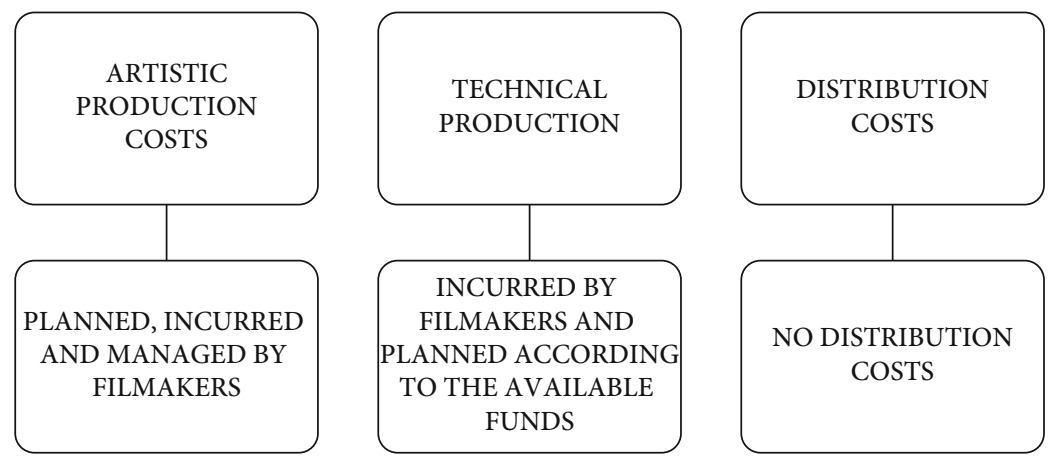

FIGURE 4.10 Costs of audiovisual web products 
driven products, such as branded web series and fashion films. These products are promoted and sponsored by OTT to expand their offer of original contents or by a given company in order to promote a brand or a product. In these cases, the filmmakers assume the role of "executive filmmakers" whose task is to simply package the product, conveying a specific message, in a specific editorial style accepted by the promotersponsor. The budget of such productions may be significantly higher than average and it depends strongly on the funding coming from the OTT or from the sponsoring company.

\section{Revenues of audiovisual web products}

The common feature of native web products is their capacity to generate low revenues when compared to traditional audiovisual products. They are designed for the web and their only distribution channel is the web. At a first stage, potential revenues may be found exclusively in the exploitation of rights on the web platforms. The major revenue source for a web product, as for television products, is the sale of advertising space; when these products are released via $S V o D$, revenues from subscription fees are also relevant.

Web advertising may take a form of a video or a banner. Different platforms adopt different selling mechanisms for advertising space. It is also common to find different selling mechanism within the same platform. According to this, it is possible to distinguish: advertisingfree products, which can be accessed without seeing any advertising messages; semi-free products, with skippable messages like pre-roll, mid-roll or post-roll videos, which can be interrupted by the viewer after few seconds; and restricted-access products, containing an unskippable advertising.

Advertising-free products do note generate any revenues, the revenues from semi-free and restricted-access products depend on agreements between the platform, agents and advertisers, as well as between the platforms and the filmakers (Figure 4.11). However, the lack of transparency regarding the above-mentioned contractual arrangements hinders proper analysis of the economic dynamics of revenue generation and allocation. In general terms, the central element of agreements with advertisers is the cost per view, according to which the price is correlated to the number of viewers, and, in the case of semi-free products, to the time of permanence of the viewer in the advertising space. 


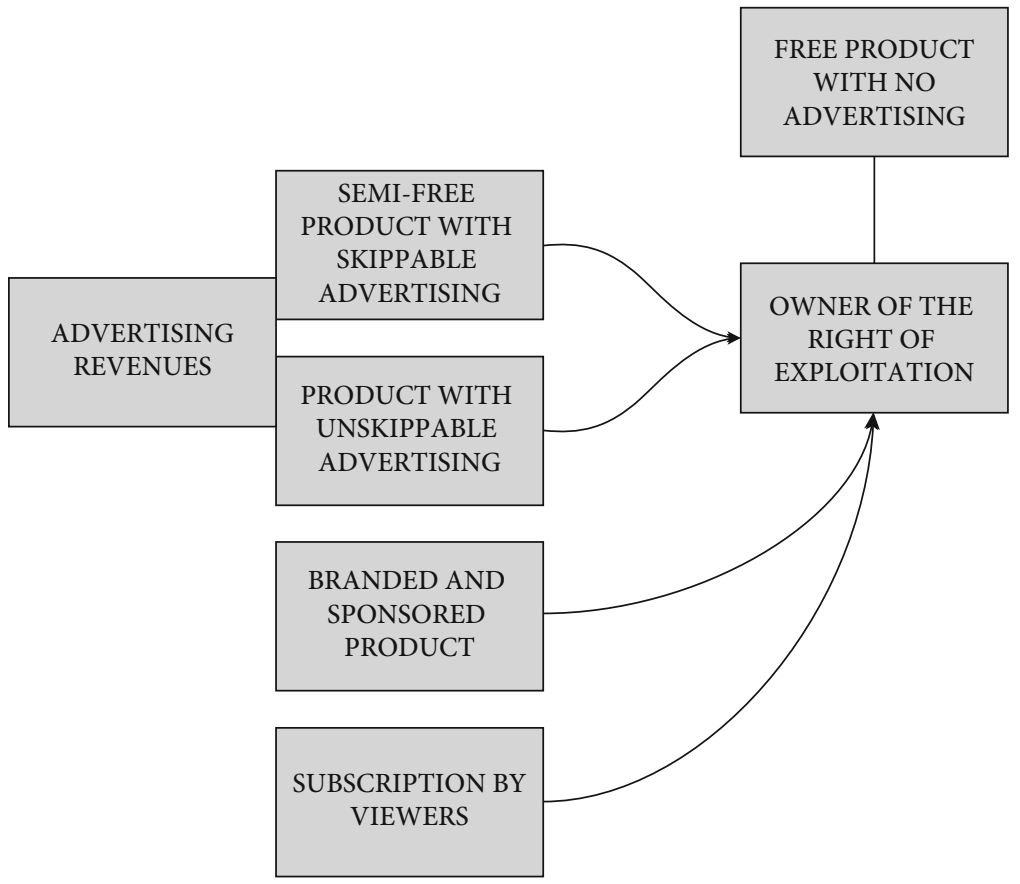

FIGURE 4.11 Revenues of audiovisual web products

In the case of sponsored products, as in the case of web series and branded fashion films, the producer fee that the sponsor pays to the filmmaker can be considered as revenue.

\section{Notes}

1 Price and value of audiovisual products will be analysed in Chapter 5 .

2 For a more detailed analysis of the relationship between the programme schedule and the product's value see Chapter 7.

3 For more details see IMCA (2001) and Adler (2003b).

cc (i) Except where otherwise noted, this work is licensed under a Creative Commons Attribution 3.0 Unported License. To view a copy of this license, visit http://creativecommons.org/licenses/by/3.0/ 